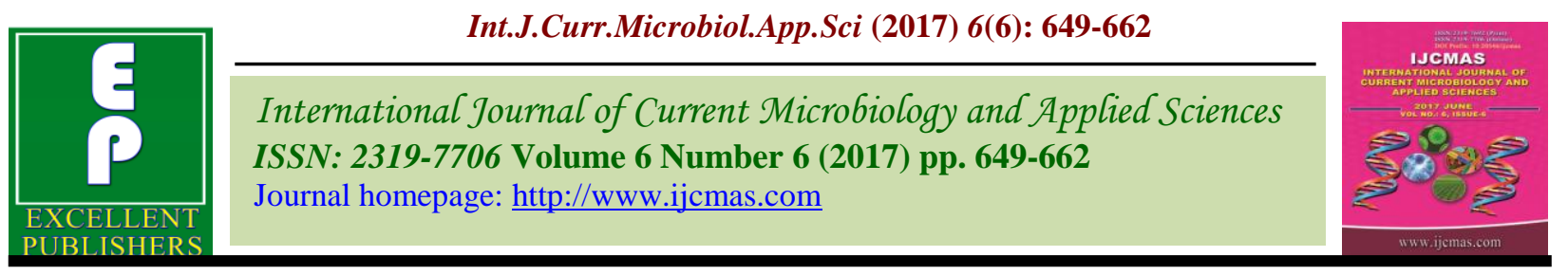

Original Research Article

https://doi.org/10.20546/ijcmas.2017.606.077

\title{
Performance Evaluation of Different Runoff Estimation Methods in North Western Tract of India
}

\author{
Sumita Chandel $^{1 *}$, M.S. Hadda ${ }^{1}$, Pratima Vaidya ${ }^{2}$ and A.K. Mahal ${ }^{3}$ \\ ${ }^{1}$ Department of Soil Science, Punjab Agricultural University, Ludhiana, Punjab-141004, India \\ ${ }^{2}$ Department of Environmental Science, Dr. Y S Parmar University of Horticuture and Forestry, \\ Nauni, Solan-173230, India \\ ${ }^{3}$ Department of Mathematics, Statistics and Physics, Punjab Agricultural University, \\ Ludhiana, Punjab-141004, India \\ *Corresponding author
}

A B S T R A C T

\begin{tabular}{|l|}
\hline Ke y w o r d s \\
Empirical method, \\
Nash Sutcliffe \\
Efficiency (NSE), \\
Root Mean Square \\
Error (RMSE), \\
SCS-CN and \\
Surface runoff. \\
\hline Article Info \\
\hline Accepted: \\
14 May 2017 \\
Available Online: \\
10 June 2017 \\
\hline
\end{tabular}

The SCS-CN method has been widely used to estimate the surface runoff from rainfall-runoff events. However in North Western tract of India this is very poorly documented. So, the main objective of the study was to propose and select the best method for the computation of surface runoff including, new empirical method and to compare this by other approaches on the bases of Root mean square error (RMSE), Nash Sutcliffe efficiency (NSE), Coefficient of determination (R2), PB (Per cent biasness) and residual error. Rainfall-runoff data from Patiala-Ki-Rao and Saleran watershed was processed to compute the surface runoff. Five different methods including the original SCS-CN method were investigated and score was given to each method on the basis of different statistical performance tools. The results demonstrated that highest score was obtained by empirical method (M5), over the other methods i.e. 19 followed by M1 (13), M2 (11), M3 (9) and M4 (8). The results demonstrated that empirical method can be a better option in north western part of India for the estimation of the surface runoff.

\section{Introduction}

For the estimation of global supply of water observed or simulated runoff data are generally used. All the general conservation models (GCMs) that provide future climate projection, use some kind of land surface models (LSM). These current land surface models (LSM) can simulate monthly river runoff considerably well, provided that the precipitated and other forcing input data for the LSMs are accurate enough (Oki et al., 1991). It is highly possible that LSMs will be directly used for the water resources projections in the future when GCMs will simulate the hydrological cycle with enough accuracy. Event-based rainfall-runoff modelling process plays a very crucial role in the hydrology. The rainfall-runoff process is affected by various physical factors and their interactions like predominant climatic scenarios to the runoff mechanism, passing through the interactions between surface and subsurface layers, vegetation and soil 
characteristics. This leads to the uncertainty in the prediction of surface runoff in ungauged watersheds and is very time consuming (Fan et al., 2013).

The estimation regarding the amount and reliability of surface runoff is a vital step for sustainable water resource management system (Tessema et al., 2015). Thus the development of the new tools or procedures and their testing indicates the usefulness to estimate runoff by employing daily rainfallrunoff events data from the unguaged watershed assumes significance.

The north western tract of the India, located in the Shiwalik belt of lower Himalayas, locally known as Kandi area, is considered as one of the eight most degraded and fragile agroecosystems of the country (Dogra, 2000). Runoff and soil erosion by water is a serious problem, where 20 to 45 per cent of annual rainfall is lost as surface runoff (Hadda et al., 2000). Rainfall variability is more in the winter months over the summer months in the area (Kukal and Bawa, 2013).The annual erosion rate in the area is more than $80 \mathrm{Mg}$ ha- 1 year $^{-1}$ however in larger watershed it is as high as $244 \mathrm{Mg} \mathrm{ha}^{-1} \operatorname{year}^{-1}$ (Sur and Ghuman, 1994). This suggested that some soil and water conservation protection policies are very much needed in area. Sustainability of the agriculture can be increased by planned land use and conservation measures, which are very crucial in the optimization of the land and water resources. To achieve this, estimation of surface runoff on a watershed is of foremost importance. As each watershed is unique in its characteristics, it becomes labour intensive and time consuming to install the gauging stations to monitor the runoff in them.

There are several approaches proposed in literature to estimate the runoff in the unguaged watersheds. Among them, SCS-CN method (recently called Natural Resource Conservation Service Curve Number method (NRCS-CN) developed by USDA, is widely used because of its simplicity and applicability, with the fact that it combines most relevant factors such as soil type, land use, treatment and surface condition, in a single parameter i.e. curve number (NRCS, 2009). But according to Ebrahimian (2012) the slope is not considered as an effective parameter on runoff rate in NRCS-CN method. Because the cultivated land in the United States has slopes of less than 5\%, and this range does not influence the curve number to a great extent. Above all initial abstraction ratio $(\lambda)$ is not a constant, but vary from storm to storm, or watershed to watershed, and predict very high runoff. However, in North western tract of India, slope steepness varies from 1 to as large as 35 per cent in watersheds. Owing to spatial and temporal variability of rainfall and associated soil moisture account, NRCS-CN method administers variability in runoff computation (Pounce and Hawkins, 1996; Sahu et al., 2007). Beside this, the constant initial abstraction ratio $(\lambda)$ in the SCS-CN methodology, which largely depends on climatic condition, is the most ambiguous assumption. Thus, it is not justifiable to consider this relationship for quantification of surface runoff and requires considerable refinement. Therefore, applicability of $\mathrm{CN}$ method in NW tract of India comprising submontaneous Punjab should be evaluated prior to being used for management and planning purpose.

Other than this, a special form of NRCS-CN method was represented by Crazier and Hawkins (1984) with initial abstraction ratio $(\lambda)$ zero showed the best fit model for computation of surface runoff. While, Woodward et al., (2003) identified 0.05 as the best fit value for 252 out of 307 watersheds of the USA. The initial abstraction ratio, using 
the event rainfall-runoff data, varied from 0.010 to 0.154 (Shi et al., 2009). In submontane Punjab, initial abstraction ratio $(\mathrm{Ia} / \mathrm{S})$ of 0.05 performed better that that over as $\mathrm{Ia} / \mathrm{S}=0.2$ (Singh, 2014). Contrary to thisJain et al., (2006) generalized the new form of equation to compute runoff from the rainfall data. They reported that by using $\lambda=0.3$, better results were obtained than that in the original NRCS-CN method, and recommended the use of the same for field application. So, there is still a great controversy that which approach must be used reliably for a particular area. Keeping these limitations in mind a new empirical equation has been proposed to compute the surface runoff for NW tract of India. So, the performance of the proposed empirical equation was evaluated over the other methods proposed in literature i.e. original NRCS-CN, Crazier and Hawkins (1984), Woodward et al., (2003) and Jain et al., (2006) etc. With this background the objective of the study was to propose a simple and empirical approach using rainfall-runoff data, over the other approaches for the estimation of surface runoff and to evaluate the performance of proposed approach over the other approaches for goodness of fit procedures in the area.

\section{Materials and Methods}

\section{Study area}

The study was conducted in the north-eastern part of Punjab i.e. Patiala-Ki-Rao and Saleran watershed representing north western part of India, located in the Shiwaliks of lower Himalayas. The area falls in $30^{\circ} 40^{\prime}$ to $32^{\circ} 30^{\prime}$ $\mathrm{N}$ latitude and $75^{\circ} 30^{\prime}$ to $76^{\circ} 40^{\prime} \mathrm{E}$ longitude at an elevation of $415 \mathrm{~m}$ above mean sea level. The climate of the region is semi-aridsubtropical with warm summer and cold winters. The mean annualsummer and winter temperatures in the region varied from 15 to $22^{\circ} \mathrm{C}$ and 5 to $6^{\circ} \mathrm{C}$, respectively. The area received an annual average rainfall of $950 \pm 290 \mathrm{~mm}$. The rainfall distribution is bimodal with most of the rains occur during the months of June to September (75-80 per cent), remaining 20-25 per cent occurs in the months of October to March. Huge runoff and soil erosion occur during the high intensity and short duration rainstorms received in the area (Hadda et al., 2000). The soils of the area remain dry for 4-5 months in a year and qualified for ustic soil moisture regime (Soil Survey Staff, 1975). Shallow soil depth and stoniness in the region generates rapid runoff due to low storage and water holding capacity. Soils in the region are generally loamy sand to sandy loam, well drained and highly erodible (Kukal et al., 2013). Location map described the Patiala Ki Rao (PKR) and Saleran watershed in the figure 1 .

The description on watershed area, slope, steepness and important data on rainfall years, number of rainstroms, mean rainfall and corresponding runoff per storm is enlisted in table 1. Data on daily rainfall and runoff (1985-1999) for Patiala-Ki-Rao \# and (1993, 1995 and 1995) Saleran\#\# watersheds was collected from the secondary sources viz., reports, and processed for the study.

Detail description of the different rainfallrunoff methods which were brought into play for the computation of surface runoff are described below.

\section{Original SCS-CN method (NRCS-CN)-M1}

The SCS-CN (SCS, 1972) method is based on a water balance and two fundamental hypotheses which can be expressed as:

$$
\mathrm{P}=\mathrm{Ia}+\mathrm{F}+\mathrm{Q}
$$

Where, $\mathrm{P}$ is precipitation $(\mathrm{mm})$, Ia is the initial abstraction $(\mathrm{mm}), \mathrm{F}$ is cumulative 
infiltration excluding Ia and $\mathrm{Q}$ is the direct runoff $(\mathrm{mm})$. The popular form SCS-CN method can be written as;

$Q=\frac{(P-I a)^{2}}{(P-I a+S)} \quad P \geq I a, \quad$ else $Q=0$

$\mathrm{Ia}=\mathrm{hS}$

Where, $\mathrm{S}=$ maximum potential retention $(\mathrm{mm}), \lambda=$ initial abstraction coefficient. Here all the variables, except $\lambda$ are dimensional $[\mathrm{L}]$ quantities. Ia, is assumed as a fraction of S. It has been taken as 20 per cent of the maximum potential retention. So, the equation 2 can be rewritten as;

$Q=\frac{(P-0.25)^{2}}{(P+0.85)} \quad P \geq 0.25$,else $Q=0$

For the available rainfall and runoff events, the values of $\mathrm{S}$ was obtained using algebraic calculations (Hawkins, 1993) as proposed in equation 5 .

$$
S=5\left[(P+2 Q)-\sqrt{4 Q^{2}+5 P Q}\right]
$$

For unguaged watershed, $\lambda=0.2$, the parameter $\mathrm{S}$ can be expressed as mentioned below.

$$
S=\frac{25400}{C N}-254
$$

Here, $\mathrm{CN}$ is the curve number, depending on the land use, hydrologic soil group, hydrologic condition and antecedent moisture content (SCS, 1972).

\section{Woodward et al., (2003) method-M2}

Model fitting technique with iterative least square procedure, Woodward et al., (2003) identified $\lambda=0.05$ as the best fit value for 252 out of 307 watersheds. This showed a high coefficient of determination (R2) and lower standard error than other values. So, they proposed the modified equation as below in equation 7 ;

$$
\ell=\frac{(P-0.05 S)^{2}}{(P+0.9 S)} \quad P \geq 0.05 S, \quad \text { else } Q=0
$$

\section{Jain et al., (2006) method-M3}

Studying the great variation in $\lambda$ values for different watersheds,Jain et al., (2006) by using different mathematical treatment of Mishra and Singh (1999) reported that $\lambda$ varied with rainfall and runoff. They further reported that $\lambda$ is directly related with $\mathrm{S}$ and $\mathrm{P}$, rather than $\mathrm{S}$ alone. So, $\lambda=0.2$ is not valid for the watersheds other than its derivations. They generated the new equation for the computation ofIa, which can be expressed as:

$$
l a=\lambda S\left(\frac{P}{P+S}\right)^{a}=0.3 S\left(\frac{P}{P+S}\right)^{1.5}
$$

The equation 8 is the generalised form of equation 3 . The modified parameters like $\lambda=$ 0.3 and $\alpha=1.5$ were estimated by Marquardt algorithm (Marquardt, 1963). This equation performed better than the original $\mathrm{Ia}=0.2 \mathrm{~S}$, and recommended for the field applications.

\section{Crazier and Hawkins (1984) method-M4}

Crazier and Hawkins (1984) proposed a best fit model with $\lambda=0$, expressed as:

$$
Q=\left(\frac{P}{P+S}\right)^{2}
$$

\section{Empirical equation-M5}

Runoff as a function of the rainfall is plotted by scattered diagram for linear, quadratic and power functions. The function which showed 
highest coefficient of determination (R2) is selected for the estimation of the surface runoff (Fig. 2). So, the equation which can be used for the computation of the runoff in the watershed are of the type mentioned below.

\section{Empirical method}

Saleran watershed

$$
Y=0.328 \mathrm{X}-8.628
$$

Patiala-ki-Rao watershed

$Y=0.478 X-4.457$

Here, $\mathrm{Y}=$ Runoff and $\mathrm{X}=$ Rainfall

\section{Soil moisture retention parameter $(\mathbf{S})$}

In order to determine the maximum potential retention parameter asymptotic approach was applied. Rainfall -runoff events showing the runoff coefficient morethan one per cent has been discarded. Then, $\mathrm{S}$ parameter was computed by employing equation 5 .

\section{Performance criteria}

The comparative performance of the models was evaluated by root mean square error (RMSE), Nash Sutcliffe efficiency (NSE) (Nash and Suitcliff, 1970), percent biasness (PB) and coefficient of determination (R2). The computation of the RMSE, NSE, PB and $\mathrm{R} 2$ is elaborated through expression 12 to 15 .

$$
\begin{aligned}
& \mathrm{RMSE}=\sqrt{\frac{1}{\mathrm{~N}} \sum_{\mathrm{i}=1}^{\mathrm{N}}(\mathrm{Qo}-\mathrm{Qc}) \mathrm{i}^{2}} \\
& \mathrm{NSE}=1-\left[\frac{\left.\sum_{\mathrm{i}=1}^{\mathrm{n}}(\mathrm{Q} \text { oi }-\mathrm{Qei})^{2}\right)}{\sum_{\mathrm{i}=1}^{\mathrm{n}}\left(\mathrm{Q} \text { oi }-\mathrm{Q} \alpha(\text { mean })^{2}\right.}\right] \\
& R^{2}=\frac{\sum_{i=1}^{n}\left[\left(Q e i-Q e(m e a n)(Q \circ i-Q o(m e a n)]^{2}\right.\right.}{\sum_{i=1}^{\mathbb{n}}\left(Q e i-Q e(\text { mean })^{2} \sum_{i=1}^{\mathbb{n}}\left(Q_{0 i}-Q 0(\text { mean })^{2}\right.\right.}
\end{aligned}
$$

$$
\mathrm{PB}=\left[\frac{\sum_{\mathrm{i}=1}^{\mathrm{n}}\left(\mathrm{Q}_{\mathrm{Q}} \mathrm{i}-\mathrm{Q}_{\mathrm{ei}}\right)}{\sum_{\mathrm{i}=1}^{\mathrm{n}}\left(\mathrm{Q}_{\mathrm{i}}\right)}\right] \times 100(15)
$$

Where, Qoi, Qei, Qo (mean) and Qe (mean) are observed, estimated, mean of observed and mean of estimated runoff storm events $i$ to $n$, respectively. Smaller the RMSE of any particular model better will be the model to estimate runoff. The Optimum value of RMSE is 0 . The value for NSE ranged between - to 1 with optimum value 1 . If the NSE > 0.50, the model can be considered satisfactory (Moriasi et al., 2007). While according to Ritter and Munoz-Carpene (2013), if NSE > 0.65, the hydrological model can be considered satisfactory. For R2, a model can be considered satisfactory if value of R2 > 0.62 (Diaz-Ramirez et al., 2011). The $\mathrm{PB}$, represent the tendency of the model to underestimate or overestimate values, and zero represent the perfect fit of the model. The positive PB value for model indicates underestimation and vice-versa.

The evaluation criteria for different performance ratings using RMSE-based model limitation, NSE, R2, and PB is described in table 2. The quantitative assessment of the models was made and graded on the basis of the statistics obtained from the data. The rank of 1 to 5 were assigned to show the RMSE, NSE, R2 and PB values were in the ascending order (lowest to highest), corresponding score is provided, for example, rank 1 showed the best performance therefore the highest score of 5 was assigned to it. Whereas for rank 5, score 1 was assigned.

\section{Results and Discussion}

The information on the soil moisture retention parameter computed by rainfall-runoff relationship is presented in table 3 . The mean of soil moisture retention parameter (S) was reported to be $54.2 \mathrm{~mm}$ in Patiala-Ki-Rao 
with median value $43.9 \mathrm{~mm}$. However in Saleran watershed mean $S$ parameter was found to be $120.9 \mathrm{~mm}$, with the median value $108.4 \mathrm{~mm}$. The $\mathrm{S}$ parameter computed for Patiala- Ki-Rao showed $43 \mathrm{~mm}$ of standard deviation and 80.6 per cent of the coefficient of variation (CV) whereas, for Saleran watershed it showed $72.4 \mathrm{~mm}$ of the standard deviation and 59.9 per cent of the coefficient of variation. The higher soil moisture retention in the Saleran watershed is attributed to the more vegetative cover compared to Patiala-Ki-Rao (Table 2).

The variation of the runoff estimated by employing all the methods under study in both the watersheds is presented in tables 4 and 5. Average rainfall during the year 1985 to 1999 in Patiala-Ki-Rao watershed was 43.9 $\mathrm{mm}$ corresponding to which $16.6 \mathrm{~mm}$ of the runoff the observed.

In comparison to the observed runoff $\mathrm{M}$ 1, M2, M3, M4 and M5 estimated mean runoff of $15.9 \mathrm{~mm}, 20.1 \mathrm{~mm}, 4.4 \mathrm{~mm}, 22.4 \mathrm{~mm}$ and $16.8 \mathrm{~mm}$, respectively. Similarly, in Saleran watershed the average rainfall during, 1993, 1995 and 1997 was $45.9 \mathrm{~mm}$ corresponding to which $6.4 \mathrm{~mm}$ of the runoff was observed. While, M1, M2, M3, M4 and M5 estimated about 10.2, 14.8, 4.7, 17.1 and $6.6 \mathrm{~mm}$ of the runoff, correspondingly. This variation in runoff estimated by M1, M2, M3 and M4 is attributed to the rainfall intensity, duration and to its spatial and temporal distribution, which had a great influence on the surface runoff, but not been included in these methods (Wang et al., 2015, Azmal et al., 2016), secondly, the slope steepness, which is the most important factor affecting the runoff, is missing in all these methods (Caplot, 2003; Wang 2015). While, the runoff estimated by M5 showed a great closeness to the observed runoff, as in this method the equation is generated by regressing the observed runoff and rainfall of this particular area.
The box and whisker plot in figure 3 is showing the variation in the observed rainfall and estimated runoff computed by the different methods in both the watersheds. The M1 (original SCS-CN), M2 (Woodward et al., 2003), M4 (Cazier and Hawkins, 1984) showed more variation than that the M3 (Jain et al., 2003), and M5 (empirical approach) which is clearly visible from figure 3 . The whisker of the M5 is comparable with the observed runoff as compared to the other methods.

\section{Performance evaluation}

Figure 4 depicts the line diagram of the RMSE values resulting from the application of the all the five methods or approaches to the rainfall-runoff dataset in both watersheds. The resulting RMSE values from different methods M1 to M5 were 14.2, 15.1, 20.8, 15.9, 12.1 and $11.01 \mathrm{~mm}$ respectively, for Patiala-Ki-Rao watershed, while for Saleran watershed RMSE were 15.6, 19.8, 14.9, 21.6, 9.0 and $8.9 \mathrm{~mm}$, respectively (Table 6). M5 indicated minimum of RMSE, while M3 and M4 indicated maximum. Based on the RMSE, values M5 model performed best (Fig 4a). M5 reported lowest of the RMSE in both in micro-watersheds.

The Nash-Sutcliffe efficiency (NSE) which provides a quantitative assessment of the closeness of the output of any methods to its observed data behavior (Azmal et al., 2016) showed negative efficiency $-0.19,-0.24$ and -0.42 in M2, M3 and M4, respectively in both the watersheds (Fig. 4b). It suggests not using these models in theses watersheds. While the models M5showed the NSE 0.68 for Patiala $\mathrm{Ki}$ - Raoand 0.75 for Saleran watershed. Like the RMSE, the highest efficacy was indicated by the M5 in both the watershed, followed by others. The average NSE showed the performance of different methods in the decreasing order; M5 (0.72) > M1 (0.34) > M2 (0.08) > M3 (0.04) > M4 (-0.07) . 
Table.1 Some characteristics and statistics of rainfall in different watersheds

\begin{tabular}{lll}
\hline Description & Patiala-Ki-Rao & Saleran \\
\hline Latitude & $30^{\circ} 40^{\prime} \mathrm{N}$ & $31^{\circ} 48^{\prime} \mathrm{N}$ \\
Longitude & $75^{\circ} 30^{\prime} \mathrm{E}$ & $75^{\circ} 38^{\prime} \mathrm{E}$ \\
Elevation (m) & 415 & 70 to 174 \\
Area (ha) & 2.97 to 15.5 & 8.75 to 42.55 \\
Slope steepness (\%) & 32.1 to 39.6 & 23.81 to 40.25 \\
Mean annual precipitation (mm) $\pm \mathrm{SD}$ & $627.3 \pm 49.3$ & $973.7 \pm 136.5$ \\
Years & $1985-1999$ & $1993,1995,1997$ \\
Number of rainfall-runoff storms & $231-246$ & $40-52$ \\
Range of rainfall per rainstorm (mm) & 38.6 to 85.1 & 33.1 to 65.5 \\
\hline
\end{tabular}

Table.2 Rating criteria using root mean square error (RMSE)-based model limitation, Nash Sutcliffe efficiency (NSE), coefficient of determination $\left(\mathrm{R}^{2}\right)$, and per cent biasness (PB)

\begin{tabular}{|c|c|c|c|c|}
\hline Rating & $\begin{array}{l}\text { RMSE-based model } \\
\text { limitation }\end{array}$ & NSE & $\mathbf{R}^{2}$ & PB (\%) \\
\hline Very good & $\mathrm{SD} \geq 3.2 \mathrm{RMSE}$ & $\geq 90$ & $R^{2}>0.82$ & 10 to -10 \\
\hline Good & $\begin{array}{l}\text { SD = } 2.2 \text { RMSE- } 3.2 \\
\text { RMSE }\end{array}$ & $\begin{array}{l}80 \leq \mathrm{NSE}< \\
90\end{array}$ & $0.72<\mathrm{R}^{2}<0.82$ & $\begin{array}{l}-15 \text { to }-25,10 \text { to } \\
15\end{array}$ \\
\hline Satisfactory & $\begin{array}{l}\text { SD=1.2 RMSE }-2.2 \\
\text { RMSE }\end{array}$ & $\begin{array}{l}65 \leq \mathrm{NSE}< \\
80\end{array}$ & $0.62<\mathrm{R}^{2}<0.72$ & 15 to 25 \\
\hline Unsatisfactory & $\mathrm{SD}<1.7 \mathrm{RMSE}$ & $\mathrm{NSE}<65$ & $\mathrm{R}^{2}<0.62$ & $>25$ and $>-25$ \\
\hline
\end{tabular}

Source:Ritter and Munoz-Carpena (2013)

Table.3 Descriptive statistics of computed soil moisture retention parameter (S) using information on recorded rainfall and runoff in two watersheds

\begin{tabular}{c|cc}
\hline & \multicolumn{2}{|c}{ Watersheds } \\
\hline Rainfall Statistics & Patiala-Ki-Rao & Saleran \\
\hline & 54.2 & 120.9 \\
Mean (mm) & 43.9 & 108.4 \\
Median (mm) & 43.0 & 72.4 \\
SD (mm) & 80.6 & 59.9 \\
CV (\%) & & \\
\hline
\end{tabular}


Table.4 Daily mean rainfall, observed and estimated runoff relationships at Patiala-Ki-Rao Watersheds

\begin{tabular}{c|c|c|ccccc}
\hline Descriptive & Rainfall & Observed & \multicolumn{5}{|c}{ Estimated Runoff $(\mathrm{mm})$} \\
\cline { 3 - 6 } Statistics & $(\mathrm{mm})$ & runoff $(\mathrm{mm})$ & $\mathrm{M} 1$ & $\mathrm{M} 2$ & $\mathrm{M} 3$ & $\mathrm{M} 4$ & M5 \\
\hline Mean & 43.9 & 16.6 & 15.9 & 20.1 & 4.4 & 22.4 & 16.8 \\
Median & 34.9 & 8.6 & 7.41 & 11.9 & 3.9 & 13.7 & 12.2 \\
Mode & 16 & 0 & 0.45 & 2.6 & 1.8 & 3.7 & 3.2 \\
SD & 31.5 & 18.7 & 22.6 & 23.8 & 2.3 & 24.3 & 15.1 \\
CV $(\%)$ & 71.7 & 112.9 & 141.6 & 116.1 & 52.3 & 108.8 & 89.9 \\
\hline
\end{tabular}

Table.5 Daily rainfall, observed and estimated runoff relationships at Saleran watershed

\begin{tabular}{c|c|c|ccccc}
\hline Descriptive & Rainfall & Observed & \multicolumn{4}{|c}{ Estimated Runoff $(\mathrm{mm})$} \\
\cline { 4 - 7 } Statistics & $(\mathrm{mm})$ & Runoff $(\mathrm{mm})$ & $\mathrm{M} 1$ & $\mathrm{M} 2$ & $\mathrm{M} 3$ & $\mathrm{M} 4$ & M5 \\
\hline mean & 45.9 & 6.4 & 10.2 & 14.8 & 4.7 & 17.1 & 6.6 \\
median & 31.5 & 0.6 & 0.9 & 4.4 & 3.4 & 6.5 & 1.7 \\
mode & 31.5 & 0 & 0.4 & 4.4 & 3.4 & 6.5 & 1.7 \\
SD & 48.3 & 18.2 & 28.8 & 32.2 & 4.3 & 33.0 & 15.8 \\
CV $(\%)$ & 105.2 & 283.3 & 286.3 & 216.7 & 91.4 & 15.8 & 246.4 \\
\hline
\end{tabular}

Table.6 RMSE, NSE, PB and R2 through different methods in watersheds

\begin{tabular}{|c|c|c|c|c|c|c|c|c|c|c|}
\hline \multirow{2}{*}{$\begin{array}{l}\text { Runoff } \\
\text { estimation } \\
\text { methods } \\
\text { Performance } \\
\text { indicators }\end{array}$} & \multicolumn{2}{|l|}{ M1 } & \multicolumn{2}{|l|}{ M2 } & \multicolumn{2}{|l|}{ M3 } & \multicolumn{2}{|l|}{ M4 } & \multicolumn{2}{|l|}{ M5 } \\
\hline & W1 & W2 & W1 & W2 & W1 & W2 & W1 & W2 & W1 & W2 \\
\hline RMSE & 14.2 & 15.6 & 15.1 & 19.8 & 20.8 & 14.9 & 15.88 & 21.6 & 11.0 & 8.9 \\
\hline NSE & 0.42 & 0.26 & 0.35 & -0.19 & -0.24 & 0.32 & 0.28 & -0.42 & 0.68 & 0.75 \\
\hline PB & 4.0 & -57.7 & -22.1 & -130.0 & 73.6 & 27.2 & -33.0 & -165.4 & 0.12 & 0.22 \\
\hline $\mathrm{R}^{2}$ & 0.606 & 0.782 & 0.620 & 0.782 & 0.658 & 0.677 & 0.623 & 0.783 & 0.649 & 0.754 \\
\hline
\end{tabular}

W1 is Patila-Ki-Rao watersheds and W2 is Saleran watersheds

Table.7 Score in relation to performance indicators and runoff Estimation methods of two watersheds

\begin{tabular}{|c|c|c|c|c|c|}
\hline \multirow{2}{*}{$\begin{array}{l}\text { Performance } \\
\quad \text { Indicator } \\
\text { Runoff } \\
\text { estimation } \\
\text { methods }\end{array}$} & RMSE & NSE & PB & $\mathrm{R}^{2}$ & \multirow[t]{2}{*}{ Total Score } \\
\hline & & & & & \\
\hline M1 & 4 & 4 & 3 & 2 & 13 \\
\hline M2 & 3 & 3 & 2 & 3 & 11 \\
\hline M3 & 2 & 2 & 4 & 1 & 9 \\
\hline M4 & 1 & 1 & 1 & 5 & 8 \\
\hline M5 & 5 & 5 & 5 & 4 & 19 \\
\hline
\end{tabular}


Fig.1 Location map of Saleran and Patiala-Ki-Rao watersheds

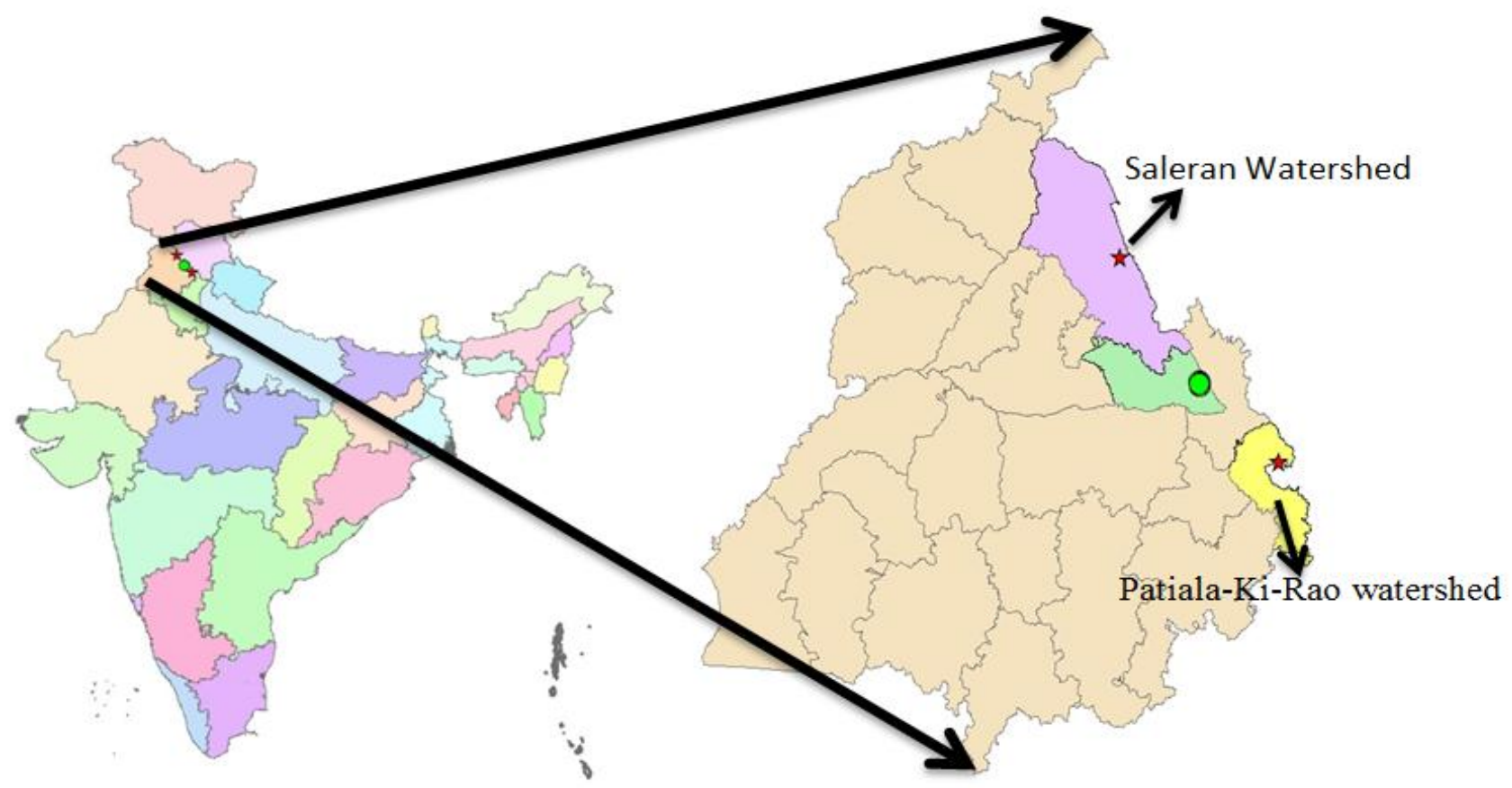

Fig.2 (a) Relationship between rainfall and observed runoff for Patiala-Ki-Rao

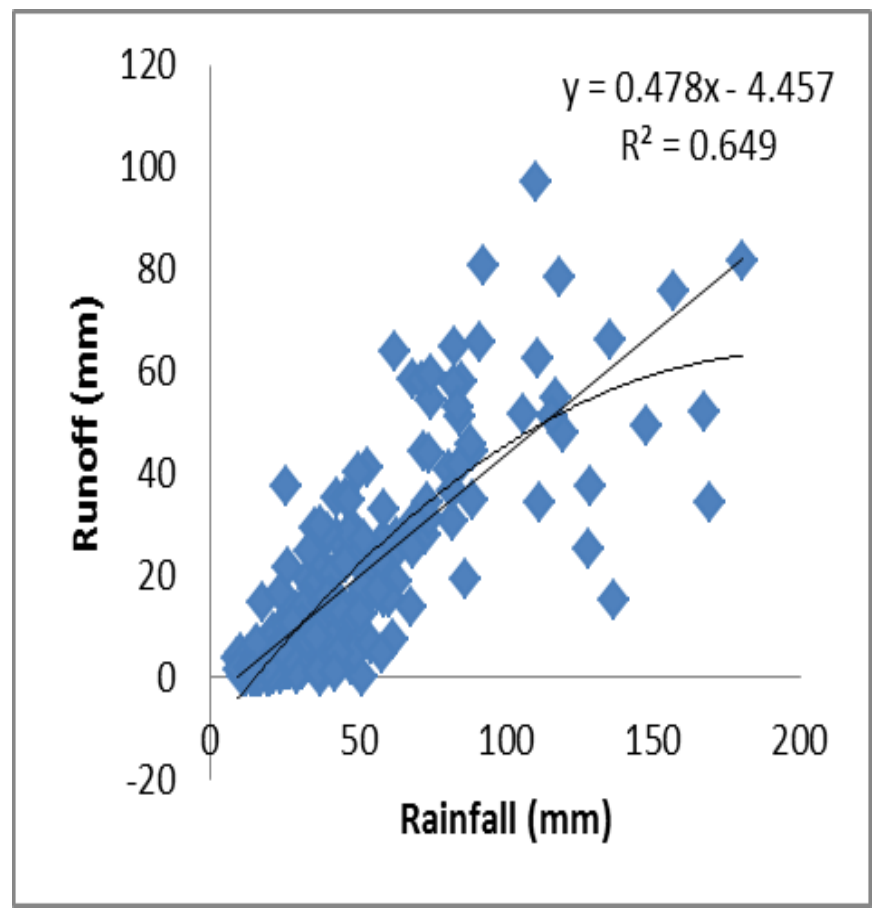

Fig.2 (b) Relationship between rainfall and observed runoff for Saleran

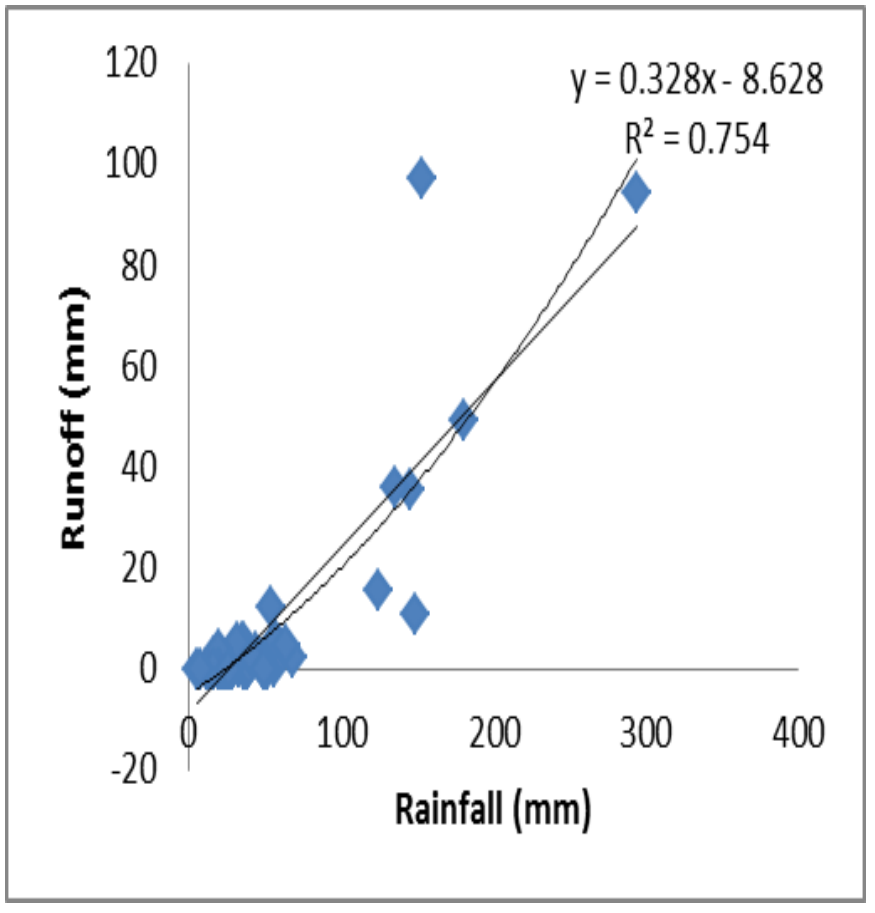


Fig.3 Mean of observed and estimated runoff at Patiala-Ki Rao and Saleran watersheds

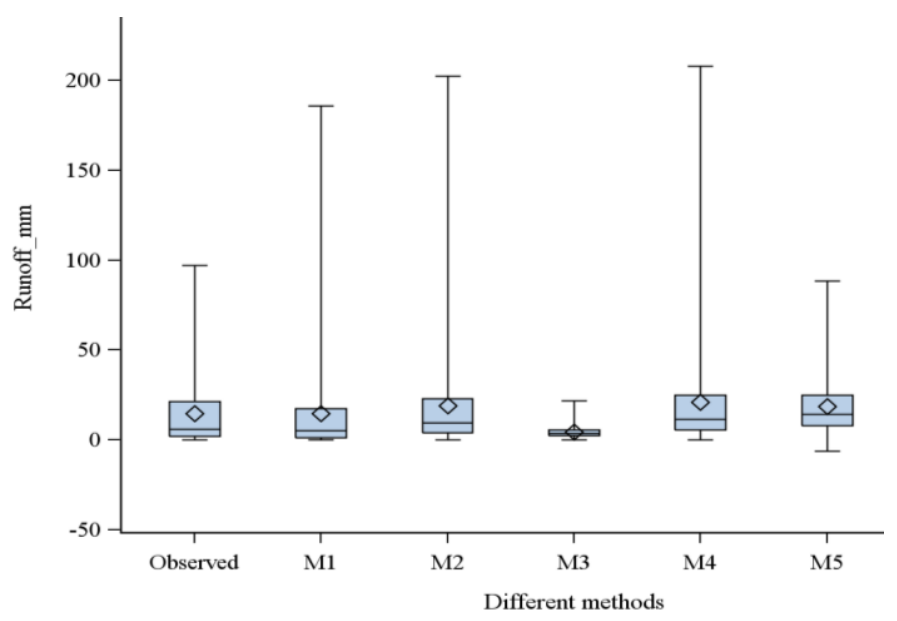

Fig.4 Performance indicators in relation to different estimation methods in two watersheds

a)
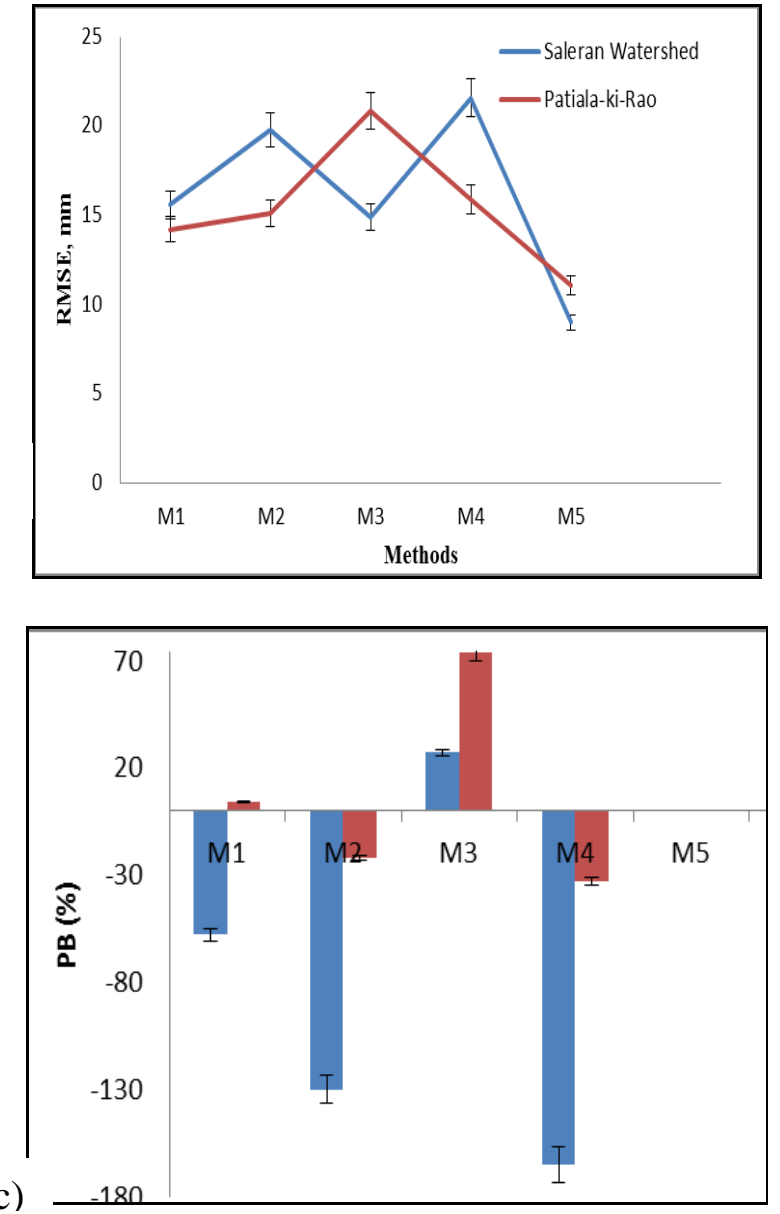

b)

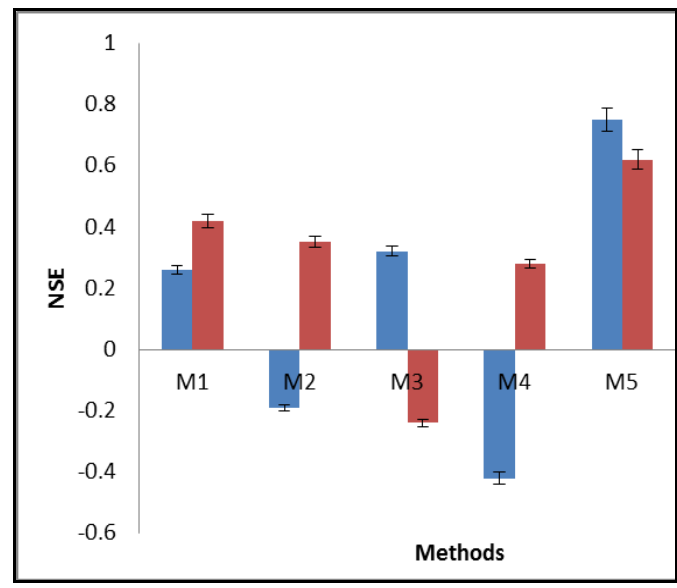

d)

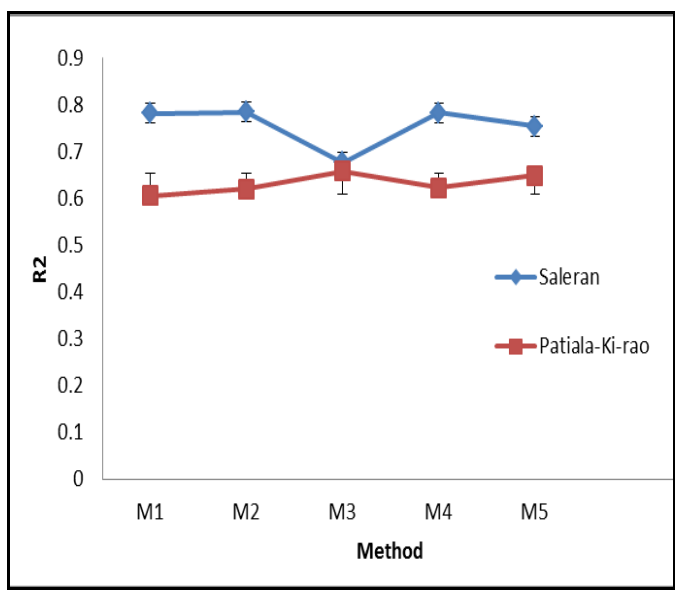


Fig.5 Distribution of the mean residual errors through box and whisker plots under different runoff estimation methods in two watersheds

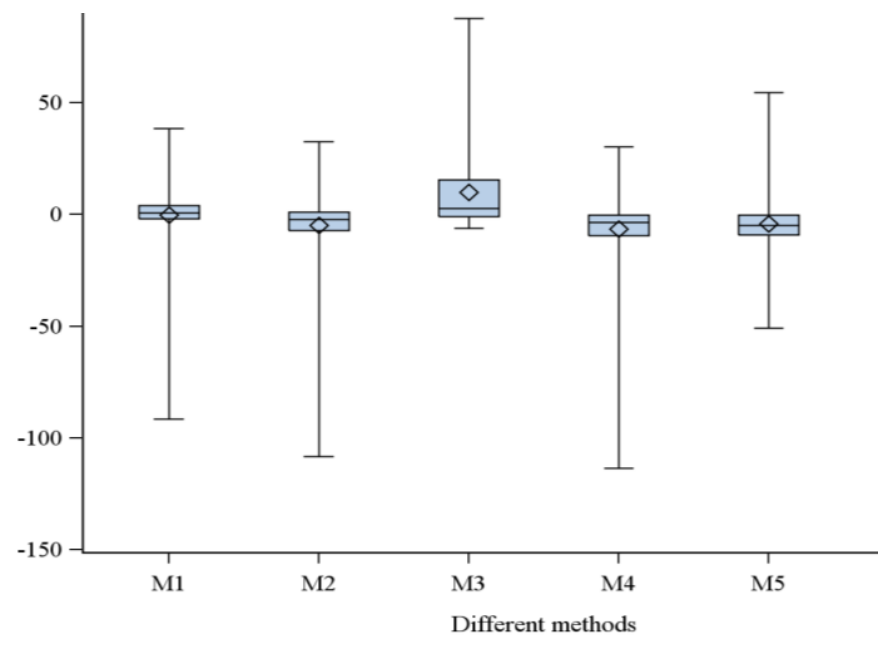

The evaluation of the model can also be judged by the per cent biasness (PB) depicted in figure $4 \mathrm{c}$. The $\mathrm{PB}$ values, which are statistically determined for M1 to M5. Almost every method showed the unsatisfactory results except for M5 i.e. empirical method. The values of the PB varied from -33.0 to $73.6(\%)$ in Patiala-Ki-Rao watershed, while for Saleran watershed it varied from -165.4 to $27.2(\%)$. The empirical method showed the best performance in both the watersheds. In addition to this average coefficient of determination (R2), which indicates the correspondence of the observed and estimated runoff, was found maximum in M4 (0.703) followed by M5 (0.702), M2 (0.701), M3 (0.667) and M1 (0.694).

Comparing the observed versus estimated runoff by computation of the residual error (E) is shown in figure 5 with the help of the box and whisker plot. The model M3 showed the highest of the residual error as there was much variation in the observed and estimated runoff, which is clearly indicated by the box and whisker's interquartile range. While in M1 and M5 this residual error is much less, as indicated by lower interquartile range.
Further, the median value of residual error in case of M5 and M1 corresponds to Zero residual value, while this is not the case with the M3 and M4. This also indicated the acceptably of M5 and M1 method in the study area.

Using the overall mean RMSE, NSE, PB and $\mathrm{R} 2$, any method which was having the minimum average RMSE, highest average NSE and coefficient of determination, rank 1 was assigned to it and corresponding score of 5 was given. Ranks and scores for model evaluation parameters have been listed in table 7 .

By using overall mean RMSE and ranking along with the scores, best method was M5, which was assigned rank 1 and score 5 followed by M1 having rank 2 and score 4 . The M4 ranked lowest with the lowest score. Similarly, when the methods were evaluated on the basis of the NSE, the first rank was given to the empirical method (M5) with the highest score i.e. 5, while the lowest rank and lowest scores were assigned to again M4 i.e. Crazier and Hawkins (1984) method. On the basis of per cent biasness (PB) highest rank 
and scores were assigned to the empirical method (M5). However, using R2 as the yardstick for the method evaluations, the highest rank was assigned to the M4 with the maximum score followed by the M5, while the lowest score was assigned to the M3 i.e. 1 with the rank 5. On combining the scores corresponding to the different evaluation parameters, M5 performed best (Score 19) while M4 performed worst (Score 8) in the runoff estimation. The empirical method outperformed in both the watersheds. The order of performance followed the trend: M5 (19) > M1 (13) > M2 (11) > M3 (9) > M4 (8). The overall statistical empirical model performance parameters namely RMSE of 4.6, correlation coefficient of 0.96 , per cent error of 11.4 , and model efficiency of $87.5 \%$, for the watershed indicated reasonably accurate simulation of runoff by the model (Yousuf et al., 2015). The results of the performance evaluation suggested to use empirical model that is simple and requires information only on rainfall depth from unguaged watersheds to estimate runoff reasonably accurately.

In conclusion, the surface runoff was estimated by different methods using rainfall runoff event analysis from Patiala-Ki Rao and Saleran watershed. The following conclusion can be drawn from this study i.e. proposed empirical method (M5) outperformed, on the basis of RMSE, NSE, PB, residual error and coefficient of determination as compared to original SCS-CN and other methods. Runoff as a function of rainfall holds a key factor in surface runoff estimation. So, regression equation $\mathrm{Y}=0.328 \mathrm{X}-8.628$ for Patiala-KiRao and $Y=0.478 X-4.457$ for Saleran watershed can be exploited for runoff estimation in this particular area. Simply, by putting the value of rainfall, surface runoff can be predicted easily. Therefore, the proposed empirical approach can be a viable alternative to the other methods evaluated to estimate runoff and can be recommended for field use. Further, lots of research needs to be done in the area of surface runoff estimation models/methods as there are still millions of controversies.

\section{Acknowledgements}

The authors express sincere thanks to Dr H S Sur, Ex-Sr Consultant Planning Commission, GOI for providing daily measured rainfall and runoff data for Patiala- Ki- Rao watershed, SAS Nagar and the financial help provided by the department of Science and Technology, GOI in the form of INSPIRE fellowship during the doctoral program to the first author.

\section{References}

Azmal, M, Ahn, J.H. and Kim, T.W. 2016. Excess strom water quantification in ungauged watershed using an event based modified NRCS model. Water Res. Manage., 30: 1433-1448. DOI: 10.1007/s 11269-016-1231-z

Cazier, D.J. and Hawkins, R.H. 1984. Regional application of the curve number method. Water today and tomorrow. Proc. ASCE Irrigation and Drainage Division Special Conf., ASCE. New York, 710.

Chaplot, V.M. and Bissonnais, Y.L. 2003. Runoff features for inter-rill erosion at different rainfall intensities, slope lengths, and gradients in an agricultural loessial hill slope. Soil Soc. Am. J., 67: 844-851.

Diaz-Ramirez, J.N., Mc Anally, W.H. and Martin, J.L. 2011. Analysis of hydrological processes applying the HSPF model in selected watersheds in Alabama, Mississippi, and Puerto Rico. Appl. Engi. Agri., 27(6): 937-954.

Dogra, A.S. 2000. Natural resource conservation and economic 
development through watershed management in Punjab Shivaliks. Pp. 145-56. In: Mittal SP, Aggarwal RK, Samra J.S. (eds), Fifty years of research on sustainable resource management in Shivaliks. CSWCRTI, Research Centre, Chandigarh, India.

Ebrahimian, M., Nuruddin, A.A., MohdSoom, M.A.B. and Sood, A.M. 2012. Application of NRCS-curve number method for runoff estimation in a mountainous watershed. Caspian $J$. Environ. Sci., 10: 103-114.

Fan, F, Deng, Y., Hu, X. and Weng, Q. 2013. Estimating composite curve number using an improved SCS-CN method with remotely sensed variables in Guangzhou, China. Remote Sens., 5(3): 1425 .

Hadda, M.S., Khera, K.S. and Kukal, S.S. 2000. Soil and water conservation practices and productivity in northernwestern submontane tract of India. Indian J. Soil Conserv., 28: 187-92.

Hadda, M.S., Khera, K.S. and Kukal, S.S. 2000. Soil and water conservation practices and productivity in northernwestern submontane tract of India. $J$. Soil Conserv., 28: 187-92.

Hadda, M.S., Sandhu, B.S. and Singh, T. 2002. A runoff model for microwatershed in North-Western tract of India. J. Punjab Acad. Sci., 1: 1-8.

Jain, M.K., Mishra, S.K., Suresh, Babu. P. and Venugipal, K. 2006. On the Ia-S relation of the SCS-CN method. Nordic J. Hydrol., 37(3): 261-275. doi: 10.2166/nh.2006.011

Kukal, S.S. and Bawa, S.S. 2013. Temporal variations in runoff and soil loss in relation to soil conservation practices in catchments in Shiwaliks of lower Himalayas. Int. J. Soil Water Conserv. Res., 1: 19-25.

Moriasi, D.N., Arnold, J.G., Van, Liew. M.W., Binger, R.L., Harmel, R.D. and
Veith, T. 2007. Model evaluation guidelines for systematic quantification of accuracy in watershed simulations. Trans ASABE, 50(3): 885-900. DOI: 10.1.1532.2506

Nash, J.E. and Sutcliffe, J.V. 1970. River flow forecasting through conceptual models: Part I- A discussion of principles. J. Hydrol., 10: 282-290. doi: 10.1016/0022-1694(70)90255-6

NRCS. 2009. National Engineering Handbook, Section 4, Hydrology, Version 2009. National Engineering Division, $U$ S Department of Agriculture, Washington, DC.

Oki, T., Nishimura, T. and Sirmeyer, P. 1999. Assessment of land surface models in major river basins of the globle using total runoff integrating pathways (TRIP). J. Meteorol. Soc. Japan, 77: 235-255.

Pounce, V.M. and Hawkins, R.H. 1996. Runoff curve number: Has it reached maturity? J. Hydrol. Engi., 11: 11-19. doi: 1084-0699/96/0001-0011-0019

Ritter, A. and Munoz-carpena, R. 2013. Performance evaluation of hydrological models: Statistical significance for reducing subjectivity in goodness of fit assessment. J. Hydrol., 480: 33-45. doi: 10.1016/j.jhydrol.2012.12.004

Sahu, R.K., Mishra, S.K., Eldho, T.I. and Jain, M.K. 2007. An advanced soil moisture accounting procedure for SCS curve number method. Hydrol. Processes, 21: 2872-2881. doi: 10.1002/hyp.6503

SCS. 1972. National Engineering Handbook, Section 4, Hydrology. Soil Conservation Service, US Department of Agriculture, Washigton DC.

Shi, Z.H., Chen, L.D., Fang, N.F., Qin, D.F. and Cai, C.F. 2009. Research on SCS$\mathrm{CN}$ initial abstraction ratio using rainfall runoff event analysis in the three Gorges Area, China. Catina, 
77(1): $\quad 1-7 . \quad$ doi: 10.1016/j.catena.2008.11.006

Singh, M. 2014. Simulating rainfall changes effects on runoff and soil erosion in submontane Punjab. M.Sc. Thesis, Punjab Agricultural University, Ludhiana.

Sur, H.S. and Ghuman, B.S. 1994. Soil management and rainwater conservation and use in alluvial soil under medium rainfall. Indian Soc. Soil Sci. Bull., 16: 50-55.

Soil Survey Staff. 1975. 'Soil Taxonomy'. Agriculture Handbook 436. (Soil Conservation Service, USDA: Washington, D.C.)

Tessema, S.M., Setegn, S.G. and Mortberg, U. 2015. Watershed modelling as a tool for sustainable water resource management: SWAT model application in the Awash River basin, Ethiopia. In:
Setegn, S.G. and Donoso, M.G. (eds.) Sustainability of Integrated Water Resources Management. Springer, Switzerland, Pp. 579-606. doi: 10.1007/978-3-319-12194-9_30

Wang, X.T., Wang, Y.K., Fu, B. 2006. Experimental study on runoff characteristics of slope land in Sichuan Basin. J. Soil Water Conserv., 20: 9-12. Woodward, D.E., Hawkins, R.H., Hjelmfelt, J.R., Jr, A.T., Vam, Mullem, J.A. and Quan, Q.D. 2003. Runoff curve number method: Examination of the initial abstraction ratio. Proc. world water Environ. Res. Congress, 1-10.

Yousuf, Abrar, Bhardwaj, Anil, Tiwari, A.K. and Bhatt, V.K. 2015. Modelling runoff and sediment yield from a small forest Watershed in shivalik foot-hills using WEPP model. Int. J. Agri. Sci. Res., 5: 67-78.

\section{How to cite this article:}

Sumita Chande, M. S. Hadda, Pratima Vaidya and Mahal A. K. 2017. Performance evaluation of different runoff estimation methods in north western tract of India. Int.J.Curr.Microbiol.App.Sci. 6(6): 649-662. doi: https://doi.org/10.20546/ijcmas.2017.606.077 